\title{
Teoria na sala de aula: uma reflexão sobre a leitura na universidade ${ }^{1}$
}

\author{
Márcia Lisbôa ${ }^{2}$
}

Resumo: $\mathrm{O}$ artigo discute a resistência à teoria e suas repercussões nas práticas de leitura desenvolvidas na universidade. Busca-se construir perfis tipológicos dos professores de literatura, tomando como referência a clássica dicotomia entre estudo intrínseco e estudo extrínseco da literatura. Esses tipos de professores são definidos pela metodologia que desenvolvem e pelas concepções implícitas em sua atuação pedagógica. Para concluir, retoma-se a etimologia da palavra teoria para propor um ensino que harmonize teoria e sensibilidade, cujo objetivo seja a intensificação da fruição literária.

Palavras-chave: Teoria. Ensino. Leitura. Reflexão.

No filme Sociedade dos poetas mortos ${ }^{3}$, há uma cena que sinaliza duas visões da Teoria da Literatura: de um lado, a sedução da técnica, que fascinou, e ainda fascina, o mundo acadêmico; de outro, a rejeição à teoria.

Em uma cena, o professor de Literatura ordena que os alunos arranquem as páginas do ensaio intitulado "Como ler um poema", escrito por um renomado PhD. Ao longo do filme, o espectador compreende que a proposta do texto eliminado entrava em choque com o modo como o novo professor encarava seu papel. Isso porque o ensaio rasgado afirmava que o valor de um poema deveria ser medido de forma matemática, posição frontalmente oposta àquela assumida pelo professor, que prega a poesia como experiência de vida.

$\mathrm{Na}$ ocasião em que assisti, pela primeira vez, ao citado filme, estava concluindo o curso de Letras e a iconoclastia juvenil levou-me a ver na cena aquilo que gostaria de fazer com meus alunos: rasgar a teoria e deixar que as subjetividades viessem à tona. Hoje, vejo a cena por ângulo diverso.

\footnotetext{
${ }^{1}$ Este artigo condensa e revisa ideias desenvolvidas em minha tese de doutoramento: OLIVEIRA, Márcia Lisbôa Costa de. Modos de ler: teoria e pedagogia da leitura. Tese de Doutorado apresentada à Coordenação dos Programas de Pós-graduação em Letras da Universidade Federal do Rio de Janeiro. Rio de Janeiro, $1^{\circ}$ sem. 2002.

${ }^{2}$ Doutora em Letras (Ciência da Literatura) pela Universidade Federal do Rio de Janeiro (2002). Atualmente é professora da Universidade Estácio de Sá, instituição em que atua também como coordenadora local do curso de Letras no Campus Niterói e do curso de Especialização em Literaturas de Língua Portuguesa no Campus Presidente Vargas. Desenvolve pesquisas sobre letramento acadêmico e competência leitora. E-mail: lisboa.marcia@hotmail.com.

${ }^{3}$ Dead Poets Society, 1989. Dirigido por Peter Weir. Em 1959, John Keating (Robin Williams) volta ao tradicionalíssimo internato Welton Academy para ser o novo professor de Inglês e se torna figura polêmica e mal vista pois, inspirado no carpe diem horaciano, acende nos alunos a paixão pela poesia, pela arte e a rebeldia contra as convenções sociais. Os estudantes ressuscitam a Sociedade dos Poetas Mortos, dedicada ao culto da poesia, mistério e amizade. A tensão entre disciplina e liberdade cresce, os pais dos alunos são contra os novos ideais que seus filhos descobriram e o conflito leva à tragédia. Oscar: melhor roteiro original, de Tom Schulman. Disponível em: http://www.cineclick.com.br/filmes/ficha/nomeFilme/sociedade-dos-poetas-mortos/id/4320.
} 
Textos como aquele citado no filme realmente nada acrescentam ao aluno. São "muros" entre o leitor e o texto. Foram análises desse tipo que geraram a ampla resistência à teoria (DE MAN, 1989), que hoje testemunhamos. Essa resistência é bem clara em uma anedota que figura na contracapa da tradução brasileira de Teoria literária, de Jonathan Culler (1999). O enredo, subentendido, é o seguinte: uma moça apresenta ao pai seu novo namorado e, como parte do protocolo, informa a "profissão" do rapaz". O pai espanta-se e pede que ela repita. No quadrinho que figura no livro, o pai, aliviado, afirma:

- "Você é um terrorista" [terrorist]. Graças a Deus!

- Entendi Meg afirmar que você era um teórico [theorist]".

A tradução perde um pouco do charme sem o efeito quase paronímico entre os vocábulos terrorist e theorist, mas a preferência por um terrorista denuncia bem o horror à teoria que comentamos acima. O terrorismo teórico pode ser realmente assustador, mas a verdade é que quando se compreende a funcionalidade dos conceitos para o desenvolvimento da capacidade analítico-interpretativa do indivíduo, o trabalho de leitura ganha novos contornos.

Em primeiro lugar, cabe indagar: porque as pessoas alimentam tanta ojeriza à teoria? Com certeza, alguns teóricos, como o crítico citado no filme, têm dado sua contribuição à visão da teoria como algo enfadonho, demasiado complexo e até mesmo inútil. Percebemos que o problema da relação entre ensino, teoria e literatura está diretamente relacionado à concepção sobre as funções dessa tríade. Isso se reflete no comportamento dos professores em sala de aula, por isso propomos, para desenvolver essa afirmativa, experimentar a criação de uma tipologia dos professores de Literatura.

Tomemos como ponto de partida para a criação de perfis de professores três atitudes distintas de leitura: uma puramente hedonista, uma moralizante e uma terceira, conciliatória. Desdobrando estas três hipotéticas atitudes de leitura, construiremos a seguir perfis tipológicos de professores de literatura, tomando também como referência a já clássica dicotomia entre estudo intrínseco e extrínseco da literatura. Ressalve-se, em primeiro lugar, que esses perfis não se baseiam em nenhuma pessoa real, nem pretendem caricaturar o ensino, servem-nos tão somente para encaminhar a reflexão.

Iniciemos nossa análise pela construção de perfis hipotéticos de professores que seguem a leitura intrínseca, os quais caracterizaremos como "impressionistas", "puristas" "metafísicos", "herméticos" e "tecnocratas". 
Os "impressionistas" deixam-se levar pelo gosto pessoal e entram em profundos devaneios estéticos durante a leitura. "Viajam" tanto no texto que os alunos ficam alijados do processo e, consequentemente, estão impossibilitados de compreender o sentido de suas brilhantes elucubrações subjetivas. Esses professores são herdeiros da crítica impressionista de Anatole France (1844- 1924), pois fazem "uma crítica que cultiva o gosto, procede por simpatia, fala de sua experiência, de suas reações, segundo a tradição humanista" (apud COMPAGNON, 2001, p. 140).

O século XIX foi pródigo nesse tipo de leitura, que ainda tem bastante espaço junto ao leitor comum. O respaldo filosófico de tal atitude pode ser encontrado em Kant, de cujas teses em torno da autonomia da experiência estética derivou o princípio da "Arte pela Arte" que dominou parte da cena artística no século XIX. Kant distingue o que provoca a experiência estética, que para ele é marcada pela satisfação desinteressada, e, por conseguinte, livre de pragmatismos, daquilo que é agradável ao homem e assume fins práticos. A arte define-se por uma "finalidade sem fim".

Esse modo de ler constitui o que os seguidores do New Criticism, chamaram de "falácia afetiva", "erro de leitura" que consistiria na confusão entre a obra e seu efeito no leitor. Para os New Critics, o significado de um texto existe nas palavras que o constituem e o efeito emocional desta sobre o leitor é irrelevante. Outro "erro" elencado por esses críticos é a chamada "falácia intencional", que corresponde à tentativa de compreensão da obra a partir das intenções de seu autor.

Sobre esses aspectos, porém, é preciso lembrar que, para as teorias que analisam as obras literárias sob o ângulo da recepção, a primeira falácia em princípio não existe, posto que é justamente o efeito de leitura que lhes interessa como objeto de análise. No entanto, em lugar de adotarem uma perspectiva impressionista, os teóricos da resposta do leitor buscam avaliar os recursos presentes no texto e seus possíveis efeitos de leitura, mas não lhes interessa, de forma alguma, escrever sobre o que sente ou pensa o leitor, categoria em que se inclui o crítico, por certo. Por outro lado, é unânime na crítica contemporânea a aceitação do princípio da não validade da intenção do autor como ponto de partida de qualquer trabalho de leitura.

O professor impressionista, tanto quanto o "purista metafísico", que descreveremos mais adiante é fiel à perspectiva desinteressada, mas seus pressupostos são bastante diversos.

O professor "purista metafísico" é tributário do pré-romantismo. Ele acredita que a civilização corrompe o homem, cuja comunicação essencial é pura, pré-linguística. Daí a inutilidade da Teoria, que afastaria o leitor de sua essência, manifesta na interpretação 
intensamente pessoal do mundo. Os mais ardorosos defensores desta posição muitas vezes tornam-se verdadeiros iconoclastas e passam suas vidas a destruir os ídolos da teoria.

Isso ocorre porque o "purista metafísico" traz para a leitura uma perspectiva filosófica bem definida. Repetindo os intelectuais do século XIX, reage à transformação da arte em mercadoria, bem como ao progresso burguês que macula com a técnica a humanidade do homem. É o ceticismo descrente dos rumos da sociedade que o leva a essa atitude diante da teoria. Assim, identifica qualquer tentativa de sistematização teórica com a técnica, que abomina.

Ambas as atitudes, tanto a impressionista quanto a purista, levam a um ensino que nega qualquer objetivo ou utilidade à arte literária. O que não pode ser visto, de todo, como um mau atributo, o problema é que essa percepção pode estender-se também à teoria. Para não radicalizarmos, cabe aqui citar uma ressalva do professor Vitor Manuel, que esclarece a importância dessa perspectiva estética para os estudos literários, embora critique seus excessos:

\begin{abstract}
Cabe-lhe um mérito inegável: acreditou na autonomia e na legitimidade intrínseca da literatura e difundiu o princípio de que a literatura deve realizar primordialmente valores estéticos. Todavia, esta defesa da autonomia da literatura, nas teorias da arte pela arte, conduziu frequentemente, como veremos, ao empobrecimento e à desvirtuação do fenômeno literário devido ao modo viciado como muitas vezes foi interpretada a autonomia dos valores literários e devido ao esteticismo mórbido, ao antagonismo radical entre a arte e a vida, ao amoralismo agressivo etc., que muitos dos seus representantes cultivaram (AGUIAR E SILVA, 1988, p. 88).
\end{abstract}

Já o "hedonista" focaliza apenas o prazer pessoal e, assim, acaba diminuindo a leitura literária ao reduzi-la à expressão de suas idiossincrasias. Ele é dado ao bovarismo, que embora seja um "direito assegurado a qualquer leitor" (PENNAC, 1993, quarta capa), traz pouca contribuição em termos pedagógicos. Esse gênero de devaneio vivenciado frequentemente pelo leitor comum, cuja denominação inspira-se na personagem Emma Bovary, de Flaubert, pode ser assim descrito:

(...) tendência para sonhar ilusórias felicidades e aventuras e para acreditar num sonho assim entretecido. A leitura aparece então como o excitante de um sentimentalismo ávido de quimeras, como a realização fictícia de desejos inconfessados, como forma ilusória de compensar frustrações existenciais (AGUIAR E SILVA, 1988, p. 107). 
A leitura é, em essência, rebelde e vadia (CHARTIER, 1998, p. 7) daí ser experimentada muitas vezes como espaço de sonho. Nenhum leitor apaixonado jamais negará a evasão com fator intrínseco ao exercício da leitura literária. Se o fizesse, entraria em contradição com sua própria experiência. Mas o problema do professor "impressionista" é que, ao deleitar-se na leitura, esquece, sobretudo, a finalidade do ensino. Afinal, qual a função de um solilóquio impressionista transformado em aula?

$\mathrm{Na}$ fronteira entre as análises intrínseca e extrínseca, temos o professor "hermético". Ocupado em desvelar os segredos do texto, ele dedica-se a encontrar significados nos menores detalhes. Uma vírgula, para ele, jamais será apenas um sinal de pontuação. Umberto Eco ironiza os que encarnam essa postura, chamando-os de "seguidores do véu" (ECO, 1993, p. 51). O efeito de suas leituras sobre os alunos é semelhante ao causado pelos impressionistas. A diferença entre os dois é que um devaneia pelo texto, enquanto o outro mergulha no texto à procura de suas obsessões simbólicas.

Passemos, agora, à construção dos perfis hipotéticos de professores cuja atuação pedagógica esta pautada em abordagens consideradas extrínsecas ao literário. Um tipo clássico é o "erudito", que conhece profundamente a biografia do autor, seu contexto histórico, os autores que influenciam sua produção literária, além de uma enciclopédia de informações referentes à obra e seu contexto de produção. Suas aulas são magistrais, panorâmicas, de um brilhantismo ímpar. A objeção que se pode levantar a esse tipo de abordagem, no entanto, é seu afastamento do texto. Exemplo de erudito é o professor desta anedota que circula em alguns manuais americanos de teoria literária:

Às oito horas, entra em sala de aula um célebre professor de uma importante universidade para analisar o poema "To his coy mistress", de Andrew Marvell. Depois de anunciar o objetivo da aula, começa a falar da vida do autor, de sua religião, de suas convicções políticas, de seu prestígio perante amigos e inimigos e chega a levantar hipóteses acerca de suas ideias sobre o casamento. Nessa altura, toca o sinal. O professor fecha o caderno de anotações, olha para o teto e conclui com um simpático sorriso: "Puxa, que belo poema! Que belo poema, gente! (Cf. TEIXEIRA, 2000, p. 15).

Essa aula de literatura, que consiste em um retrato do autor construído à maneira daqueles publicados pelo crítico francês Saint-Beuve (1804-1869), desconsidera absolutamente o texto, além de encerrar-se com uma declaração de puro impressionismo.

Por último, podemos mencionar os "tecnocratas". Ferrenhos defensores do método, procuram a todo custo a postura correta de leitura, preferencialmente redutível a um código ou fórmula. Criam quadros, esquemas, gráficos e assim explicam precisamente o significado 
"cientificamente autorizado" dos textos. Essa atitude crítica ora leva à aplicação pura e simples de métodos quando costuma fugir à reflexão; ora perde-se em citações e reflexões teóricas, esquecendo-se do texto. Voltaremos a abordar os problemas gerados pelos tecnocratas mais tarde.

O tipo mais característico de analista extrínseco, no entanto, é o professor “dogmático". Ele enxerga na literatura exclusivamente o viés social, tratando a obra como um sintoma da sociedade em que foi criada. Sob esse prisma, são possíveis cinco modalidades de análise, segundo Pierre Furter (Cf. ACÍZELO, 1987, p. 72):

$1^{\mathrm{a}}$ análise da posição social do poeta no tempo e no espaço; $2^{\mathrm{a}}$ estudo da significação social da obra; $3^{\text {a }}$ depreensão da imagem que a obra oferece de uma sociedade; 4 a estudo das relações existentes entre formas poéticas e estruturas sociais; $5^{\text {a }}$ análise da literatura enquanto colocação da linguagem, instituição social por excelência, em forma individual, estética, e no plano do imaginário.

Podemos considerar que apenas as quatro primeiras versões são exclusivamente extrínsecas, já que a quinta trata a linguagem literária como objeto social, situando-se, portanto, na fronteira intrínseco/extrínseco.

Depois de apontarmos os equívocos que podem caracterizar os perfis ficcionais de professores que criamos recorreremos, agora, à etimologia do vocábulo "teoria", tal como apresentada por Werner Jaeger (1957), para melhor compreendermos a função dessa disciplina como um pressuposto para práticas pedagógicas que respeitem e potencializem o texto literário.

Segundo Jaeger, o termo teoria, que é abstrato, origina-se do grego theorós e significa 'concreto'. $\theta \varepsilon \omega \rho \imath \alpha$ (teoria) é o plural coletivo de theóros, um título que se dava ao funcionário público encarregado de testemunhar a ocorrência dos jogos que se celebravam. Percebemos, então, que o theorós tinha uma função dupla. De um lado, assistia simplesmente para ver, como um espectador entre espectadores, sem intervir na marcha do jogo. Mas, de outro, inspecionava, isto é, tinha a incumbência de verificar se o jogo transcorria de acordo com as regras preestabelecidas. Teoria, em sentido próprio, é a visão de um espetáculo, visão intelectual, construção especulativa por oposição à prática, ou seja, é uma especulação ligada aos princípios e às consequências, mas desinteressada das aplicações.

Continuando com Jaeger (1957), em Platão, aparece como "ação de ver, observar". Desta maneira, o vocábulo implica um distanciamento entre o observador e o observado. A teoria, nessa acepção, não visa outra coisa que não seja a si mesma, é um conhecimento que 
está em função de si mesmo e não em função de outra coisa, o que seria arte, técnica, mas não teoria, ciência. Já $\tau \varepsilon \chi \vee \eta$ (techné), que originou a palavra técnica, relaciona-se originalmente às artes manuais, à habilidade de executar uma arte. Assim, faz referência a toda profissão baseada em determinados conhecimentos especiais, que estabelecem regras gerais a partir de conhecimentos empíricos. Consoante à análise de Jaeger, como podemos observar, o emprego que Platão e Aristóteles fazem de techné também está incluído no sentido contemporâneo do termo teoria, que se concebe geralmente em função de uma prática (JAEGER, 1957, pp. 489; $515 ; 723 ; 842-3 ; 846 ; 943-4)$.

Para que essa riqueza etimológica do vocábulo 'teoria' se faça presente no ensino, é preciso, pois, que o professor se coloque como espectador do jogo da linguagem, e como tal, formule especulações; mas, ao mesmo tempo, no momento em que o texto e os alunos são postos em diálogo, cabe a ele inspecionar, examinar, orientar leituras.

Por isso, uma grande contribuição que a teoria pode dar ao ensino de literatura é a transposição didática das características do processo teórico - relativização, rotação de pontos de vista, descentralização, problematização, contradição - criando um modo de ler que possibilite aos alunos a vivência do prazer estético pelo trabalho sobre o texto, sem perder de vista os incômodos, os perigos e as dúvidas em que incorre quem deseja experimentar linguagem poética.

Uma opção interessante é o ensino fundado na recepção, pois, assumindo essa perspectiva, o professor poderá levar a turma em sua "viagem" e, assim, compartilhar a experiência de construção de um texto coletivo de leitura. Dessa forma, a aula de literatura poderá aproximar-se mais do que vive um leitor-empírico e, consequentemente, ser mais prazerosa.

Quando a expressão pessoal dos alunos se dá num movimento de interlocução, instalando um jogo de pontos de vista, o professor torna-se mediador, portanto abdica do papel centralizador para comportar-se como um dos sujeitos-leitores. Essa posição de abertura dialógica ao convívio deveria ser o princípio fundador de toda metodologia de ensino de literatura.

Assim, podemos delinear um perfil ideal, marcado pela flexibilidade e sustentado pela aliança entre conhecimento técnico, reflexão teórica e sensibilidade, em cujas aulas de literatura a teoria funcionará como um Kama Sutra da leitura, extraindo dos textos o máximo de prazer.

\section{Referências bibliográficas:}


ACÍZELO, Roberto. Formação da Teoria da Literatura. Niterói, RJ: EDUFF, 1987.

CHARTIER, Roger. Práticas de leitura. São Paulo: Estação Liberdade, 1998.

COMPAGNON, Antoine. O demônio da teoria: literatura e senso comum. Belo Horizonte: UFMG, 2001.

CULLER, Jonathan. Teoria Literária: uma introdução. São Paulo: Beca, 1999.

DE MAN, Paul. A resistência à teoria. Lisboa: Edições 70, 1989.

ECO, Umberto. Interpretação e superinterpretacão. São Paulo: Martins Fontes, 1993.

JAEGER, Werner. Paideia: los ideales de la cultura griega. México: Fondo de Cultura Económica, 1957.

OLIVEIRA, Márcia Lisbôa Costa de. Modos de ler: teoria e pedagogia da leitura. Tese de Doutorado apresentada à Coordenação dos Programas de Pós-graduação em Letras da Universidade Federal do Rio de Janeiro. Rio de Janeiro, $1^{0}$ semestre de 2002.

PENNAC, Daniel. Como um romance. Rio de Janeiro: Rocco, 1993.

SILVA, Vitor Manuel de Aguiar e. Teoria da Literatura. 8. ed. Coimbra: Almedina, 1988 (2.v.).

TEIXEIRA, Ivan. Panorama da Crítica. Revista Cult, São Paulo, n. 11, p. 15-17, 2000.

Theory in the classroom: a reflection on reading in the university

\begin{abstract}
The article discusses the resistance to theory (De Man, 1989) and its effects on reading practices developed at the university. Typological profiles of teachers of literature are built, taking as reference the classic dichotomy between the intrinsic and extrinsic study of literature. These types of teachers are defined by their methodology and implicit in their pedagogical performance. In conclusion, it is considered the etymology of the word theory to propose an education which harmonizes sensitivity and theory, whose goal is the intensification of literary enjoyment.
\end{abstract}

Key words: Theory. Teaching. Reading. Reflection. 